\title{
CONTENT AREAS FOR CURRICULUM DEVELOPMENT: SPIRITUALITY AND SOCIAL WORK
}

\section{Raisuyah Bhagwan}

\section{INTRODUCTION}

Calls for the integration of spirituality into social work curricula emerged in the Western literature on the issue over two decades ago (Canda, 1989). Empirical enquiries in the American and British contexts proliferated, revealing a conspicuous void in spirituality education (Furman, Benson, Canda \& Grimwood, 2005; Gilligan \& Furness, 2006; Graff, 2007). They also showed strong support for the introduction of a course on spirituality and social work, thus leading many schools of social work to begin offering it as an elective in the United States (Bhagwan, 2002). In contrast, the schism between spirituality and social work in practice, education and research has been pronounced in South Africa.

The rationale for the inclusion of spirituality in education centres on the fact that social work is guided by a holistic, eco-systems perspective and social work as a profession is committed to respecting the diversity of people (Bhagwan, 2002). Literature on spirituality reflects its salience to a broad range of areas with which social work intersects viz. the elderly (Bianchi, 2005; Ewing, 2005); faith-based services (Cnaan, Boddie \& Kang, 2005b); vulnerable children and youths (Bhagwan, 2009; Kvarfordt \& Sheridan, 2007); substance abuse and incarceration (Moxley \& Washington, 2001; Redman, 2008); and HIV/AIDS and family problems (Bhagwan, 2002).

American curricula reflect that the aforementioned facets have been integrated into courses on spirituality and social work (Bhagwan, 2002). Further the Global Standards for Social Work Education and Training call specifically for the consideration of "spiritual factors" and how "religions" impact on human functioning and development (Sewpaul \& Jones, 2005:220). Scrutiny of the standards for social work qualifications in South Africa reveal no mention of religion or spirituality within the exit-level outcomes for the Bachelor in Social Work (BSW) programme (Lombard, Grobbelaar \& Pruis, 2003). The purpose of this paper is to present data from a national survey with final-year social work students with regard to components of a course on religion, spirituality and social work. Each of these components has been elaborated on to unfold specific content that can be included in a course on spirituality and social work. It is envisaged that these components can be used to guide curriculum development in this field, or that each of the areas discussed can be infused where appropriate into existing curricula. In line with this, where appropriate, the exit-level outcomes for the BSW programme are delineated in italicised print to highlight where it is possible for the integration of spirituality content to occur.

\section{METHODOLOGY \\ Data collection}

A survey questionnaire was used to collect data from social work students at schools of social work in South Africa. The questionnaire focused on students' views on spirituality in social work practice and education, their use of spiritually-based interventions and opinions regarding their appropriateness for social work, the introduction of a course on spirituality and social work in South Africa and the components of such a course on spirituality. This paper reports solely on the students' levels of agreement on content areas for a course on spirituality and social work in South Africa. 
The questionnaire was distributed to the population of final-year social work students by enlisting the assistance of heads of each school of social work. They ensured that all students received the surveys. They then posted the completed questionnaires to the researcher using a self-addressed return envelope, which had been included to facilitate the return process. Seven hundred and fourteen questionnaires were distributed, 342 surveys were completed, yielding a response rate of $47 \%$. Four schools failed to return the surveys after several follow-up calls were made.

\section{RESPONDENTS}

Most of the respondents were female (84\%), between the ages of 19-25. The sample was also predominantly African (68\%), followed by White (18\%), Coloured (12\%) and Indians (2\%). Ninety-two percent of the respondents indicated that they were Christian, $5 \%$ indicated that they followed African Traditional Religion, and 3\% identified themselves as Muslim, Hindu or Jewish.

\section{FINDINGS}

\section{Content areas for a course on religion, spirituality and social work}

Students were asked to indicate which of the following content areas they thought should be included in a course on spirituality and social work. Table 1 presents data related to respondents' levels of support for the different topics provided. They have been ranked from highest to lowest according to the levels of support received. The discussion that follows transforms these broad content areas into guidelines which contain specific information that can be built into these areas. Below each topic the exit-level outcomes (for the BSW qualification) which cohere most with the content are included in italicised print to serve as a guide in terms of where spirituality content may be incorporated.

\section{TABLE 1}

\section{RESPONDENTS' VIEWS ON SPECIFIC CONTENT AREAS FOR A COURSE ON RELIGION, SPIRITUALITY AND SOCIAL WORK}

\begin{tabular}{|c|c|c|}
\hline Content issues & No. & $\%$ \\
\hline 1. Religious and spiritual diversity & 282 & 84.9 \\
\hline 2. Dealing with religious/spiritual issues in practice & 273 & 82.2 \\
\hline 3. Interface of religious, spiritual and social work values & 266 & 80.1 \\
\hline $\begin{array}{l}\text { 4. Ethical issues: Consideration of religiously based ethical dilemmas, e.g. right to } \\
\text { abortion }\end{array}$ & 266 & 80.1 \\
\hline 5. Students' personal, spiritual and professional growth & 251 & 75.6 \\
\hline 6. Spiritually based interventions & 240 & 72.3 \\
\hline 7. Collaboration and networking with religious and spiritual organisations & 237 & 71.4 \\
\hline $\begin{array}{l}\text { 8. Functional and dysfunctional religious and or spiritual beliefs and behaviour } \\
\text { patterns }\end{array}$ & 229 & 69.0 \\
\hline 9. Religious perspectives on policy issues & 222 & 66.9 \\
\hline 10. The historical religious or spiritual roots of the profession & 217 & 65.4 \\
\hline 11. Developmental theories of spiritual and religious growth & 214 & 64.5 \\
\hline $\begin{array}{l}\text { 12. Transpersonal social work: } \\
\text { - Diagnostic skills to distinguish between genuine religious/transpersonal } \\
\text { experiences and psychopathology } \\
\text { - Theory } \\
\text { - Transpersonal healers } \\
\text { - Transpersonal experiences }\end{array}$ & $\begin{array}{l}199 \\
173 \\
170 \\
165\end{array}$ & $\begin{array}{l}59.9 \\
52.1 \\
51.2 \\
49.7\end{array}$ \\
\hline
\end{tabular}




\section{RELIGIOUS AND SPIRITUAL DIVERSITY}

(Demonstrate social work values while interacting with human diversity; analyse human behaviour with regard to the intersections of race, class, culture, ethnicity, gender, differential abilities and sexual orientation.)

Religious and spiritual diversity received the highest level of support (85\%) in terms of inclusion in the proposed course. Similar findings were made by Graff (2007) in her study with United States students $(n=324)$. Over $82 \%$ agreed that social work education should cover content on religious and spiritual diversity. Spiritual diversity, when unfolded, is not restricted solely to a study of divergent religious traditions, but embraces ethnicity, gender, sexual orientation, disability, social class, race and culture. The following sub-sections illuminate the areas requiring attention.

\section{Religious diversity}

Social work curricula should include knowledge of history, traditions, spiritual practices and experiences that occur in the realm of diverse spiritual faiths (Rothman, 2009). In a universal context Hinduism, Judaism, Christianity, Islam and Buddhism are most relevant to social work (Canda \& Furman, 1999). Locally, however, insight into those most dominant worldviews viz. Christianity, African Traditional Religion, Hinduism, Islam and Judaism - and how they interface with client's problems would be most relevant to indigenous curricula. Hodge contended that social work education should be structured around the following two goals : "(1) develop a strengths-based awareness, understanding, and competency regarding the major forms of spiritual diversity that exists among clients in a manner that reflects a given nation's spiritual demographics; and (2) develop this knowledge base in a manner that fosters sensitivity toward the various forms of religious discrimination spiritual believers encounter and engender a desire to advocate against religious discrimination" (2005:39).

Canda (1989) wrote that students can be taught to appreciate religious diversity by contrasting religious traditions or secular and religious perspectives. Traditional support systems such as religious healers can be compared and the culture- and religion-bound syndromes that characterise these worldviews can be highlighted. Even in macro-practice courses, religiouslyinspired social justice movements, e.g. the passive non-violent movement of Mahatma Gandhi and the civil rights movement of Martin Luther King, can be discussed.

Although local religious traditions should sit at the heart of indigenous spiritual diversity, education can be enhanced through an exploration of other divergent belief systems, e.g. liberation theology or Zen Buddhism (Dudley \& Helfgott, 1990), so as to strengthen an understanding of global human traditions.

\section{Ethnic diversity}

Ethnicity and religion are closely intertwined. The South African landscape is coloured by a multitude of ethnic groups, some of which flow from certain spiritual faiths. The range of ethnic groups that exist within a single religious tradition poses challenges to practitioners as the worldviews of each ethnic group differ. For example, within the Hindu faith there are those of Gujerathi, Tamil or Hindi descent. Although their religion is Hindu, each group's traditions, language patterns, customs, rituals and styles of worship are different. Even those who practise African Traditional Religion have varied beliefs and practices, depending on the geographical location of these groups. The indigenous healing methods, culture-bound syndromes and client use of transpersonal or traditional healers add to the complexity of challenges for students who need to be prepared to work in a culturally sensitive manner with their client's problems 
(Bhagwan, 2002). Whilst schools of social work in a particular geographical area can broaden students' understanding of the unique ethnic groups prevalent in their area, a respect for spirituality as it manifests across cultures should be the core thread of curricula.

About $59 \%$ of the sample indicated the need for education on culture-bound syndromes. The Diagnostic and Statistical Manual of Mental Disorders (DSM-IV) stated that "...a clinician who is unfamiliar with the nuances of an individual's cultural frame of reference may incorrectly judge as psychopathology those normal variations in behaviour, belief, or experience that are particular to the individual's culture" (American Psychiatric Association, 1994:xxiv). Practitioners who do not understand the spiritual framework of the client run the increased danger of biased and inaccurate diagnosis related to the ethnocentrism, religious assumptions and theoretical beliefs of the practitioner. Assessment must therefore explore the client's cultural, religious and spiritual beliefs (Bhagwan, 2007a). In their discussion of the cross-cultural diagnosis of schizophrenia, the authors of the DSM-IV manual warned that "ideas that may appear to be delusional in one culture (e.g. sorcery and witchcraft) may be commonly held in another. In some cultures visual or auditory hallucinations with a religious content may be a normal part of religious experience (e.g. seeing the Virgin Mary or hearing God's voice)" (American Psychiatric Association, 1994:281). Without this knowledge students may easily make a diagnosis of mental dysfunction. Information on culture-bound syndromes, particularly those prevalent locally, and proficiency in the use of the DSM-IV manual should be a part of social workers' education.

\section{Non-sectarian spiritual perspectives}

Curricula which appreciate diversity to its fullest should also strive to include content on nonsectarian spiritual perspectives, such as transpersonal theory and existentialism (Canda \& Furman, 1999). Guidelines in terms of content on transpersonal social work are presented later.

\section{Spiritual diversity and human diversity}

Diversity in gender and sexual orientation also needs consideration in spiritual diversity education. Women's spirituality provokes a range of complex and controversial issues in relation to the liberating and oppressing functions of religious traditions. The impact of patriarchal faith traditions and the role of practitioners in empowering women should receive particular emphasis in training (Canda \& Furman, 1999).

Another important area of consideration relates to diversity of sexual orientation as it intersects with issues of homosexuality. The Judeo-Christian, African Traditional Religion, Hindu and Islamic worldviews have long subjected gays and lesbians to ostracism. Social work ethics, however, prohibits discrimination, requiring that curricula contain the requisite knowledge and values for understanding people of diverse sexual orientations and for opposing discrimination and oppression. Canda and Furman (1999) summed up the task for social work education by saying that it "needs to prepare social workers for a more astute analysis of the religious and spiritual issues involved in attitudes about homosexuality and the diverse spiritual opportunities available for gay, lesbian, bisexual, and transgendered people" (1999:115).

\section{DEALING WITH RELIGIOUS/SPIRITUAL ISSUES IN PRACTICE}

(Assess client systems' social functioning; access and utilise resources appropriate to client systems' needs and strengths.)

Over $80 \%$ of the sample believed that course content should enable them to deal with religious or spiritual issues in practice. In a survey of British social workers $(n=789)$ Furman, Benson, 
Grimwood and Canda (2004) found that they believed that it was appropriate to raise issues of spirituality with clients who were facing terminal illness $(76 \%)$; those recovering from sexual abuse (42\%); those who had experienced a natural disaster $(55 \%)$; those facing bereavement (74\%); and those with difficult family relations (38\%). First of all, however, students must understand the principles underpinning spiritually sensitive practice (Bhagwan, 2002). A conceptual understanding of religion and spirituality in a social work context (Carroll, 2001) is also important to highlight that, although religion and spirituality overlap and impact on practice, there remains a dichotomous relationship between them. This is critical to avoid confusing religion with spiritually-sensitive social work practice. Religion tends to identify a person with a particular faith group and his or her participation in the activities, ceremonies and rituals of the group (Bhagwan, 2002). Definitions of spirituality in social work, however, mirror spirituality as an integral part of a person which is sacred and irreducible, a person's search for meaning and interconnectedness, and a developmental process of movement towards a sense of wholeness in oneself and with others (Canda \& Furman, 1999).

Other important facets that would need to be included are: spirituality in the context of a biopsychosocial-spiritual-environmental (BPSSE) assessment (Derezotes, 2006); knowledge and skill to undertake a spiritual history, to draw spiritual genograms and time lines; guidelines to conduct a spiritual assessment and proficiency in the use of spiritual assessment tools; and the nature of religious and spiritual problems that may emerge in practice and intervention strategies (Bhagwan, 2007b). Mystical experiences, involvement in religious cults, conversion of faith, problems that emanate from inter-religious marriage, religious dilemmas associated with homosexuality, and existential questions when faced with illness can be explored to create interesting case vignettes.

\section{INTERFACE OF RELIGIOUS, SPIRITUAL AND SOCIAL WORK VALUES}

\section{(Demonstrate social work values while interacting with human diversity.)}

Almost $80 \%$ of the sample indicated that curricula should explore the interface of religious, spiritual and social work values. Spiritual values as they relate to the core values underpinning the profession may be illuminated. The historical development of the profession as shaped and influenced by the Judeo-Christian religious tradition may also be used by educators to illustrate the interface of religious, spiritual and social work values. Derezotes (2006) suggests that the spiritual practitioner be guided by the values of service (taking responsibility for the Highest Good of people), consciousness (developing the transpersonal side of a person), love (for self, others and ecosystems), connectedness (living in interrelationship with self, others and the Cosmos). Students can be asked to reflect on and create their own set of spiritual values for practice. It is the spiritual paradigm itself which acts as the conceptual bridge between social work values and religious values in that both social work and spiritual communities "(a) work on such aspects of spiritual development as compassion, equanimity, and temperance; (b) provide service, as a part of the spiritual path, to other people, living things, and ecosystems; and (c) cooperate with other communities, as part of the spiritual path" to promote global wellbeing (Derezotes, 2009:74). These can be used as points for discussion in class.

\section{ETHICAL ISSUES}

\section{(Appraise and implement the ethical principles and values of social work.)}

Eighty percent of the sample concurred on the need for a spirituality course to cover ethical issues. This forms an important part of education as students need to explore their values and 
moral and ethical understanding of themselves, the client and the helping process. Journaling a spiritually sensitive technique can be used as a task to enable students to become more aware of their biases, prejudices and negative attitudes with explicit attention to religious, moral and spiritual concerns.

Proselytisation or moralistic judging based on spiritual beliefs is clearly not in line with a spiritually sensitive ethical relationship. Abortion, use of contraceptives, homosexuality and the use of reproductive technology are issues that have strong moral and religious dimensions linked to them (Bhagwan, 2002; Derezotes, 2006). These can impact on both the client and practitioner. For the practitioner a journey back to the values of empathy and a non-judgmental attitude need to be foremost when confronted with a client's behaviour or decisions antithetical to their own spiritual frame of reference. Northcut stressed the importance of students understanding that they are not the "spiritual guides" of clients, but need to assess and treat spiritual concerns within the traditions of their clients (2004:351). The ethical parameters surrounding the use of spiritual interventions also need to be delineated. This is discussed later. Knowledge about spirituality, self-awareness, competency and a genuine commitment to professional values (Canda, Nakashima \& Furman, 2004) are the key dimensions for teaching spirituality.

\section{STUDENTS' PERSONAL, SPIRITUAL AND PROFESSIONAL GROWTH}

(Access and utilise resources appropriate to client systems' needs and strengths.)

Seventy-six percent of the sample expressed the view that their personal spiritual growth should be incorporated into education. High levels of personal spirituality may have been a factor in students' making this request. Personal spirituality often impacts on professional work and, as indicated in the above section, students need to be aware of how personal beliefs and practices influence their work with clients.

While it is not suggested that education become the domain for personal spiritual growth, opportunities for spiritual transformation can occur during the educational process. Jacobs highlighted this by saying that "our work towards wholeness with the client requires that we engage in reflecting on our own spiritual and psychological journey" (1997:173). Education encompassing spiritual techniques such as forgiveness, journaling, art, music, dance and poetry therapies and mindful meditation (Bhagwan, 2002) may expose students to those techniques that they can use with clients and themselves to enable their own personal transformation. Writers such as Layton and Collins (2004), for example, pointed out how spirituality, specifically nature retreating, has been beneficial in coping with burnout. A nature retreat exercise coupled with mindful practice exercises and spiritual music can easily awaken students to the benefits of spirituality. Courses developed in the United States have focused on meditation as a tool for self-care and growth, an exploration of wellness and the "wounded healer paradigm", and offer opportunities for students to create and present their own spiritual rituals (Bethel, 2004:32).

\section{SPIRITUALLY-BASED INTERVENTIONS}

(Plan and implement appropriate social work intervention strategies and techniques at micro, mezzo and macro levels.)

Over $70 \%$ of the sample supported the inclusion of spiritual interventions in curricula. The above section highlights some examples of such interventions. In this area their efficacy in relation to problems clients may experience - e.g. rape, abuse, substance use; anxiety etc. - 
should also be presented (Hodge, 2006). Students can be referred to articles which detail interventions that are most suitable for a particular type of problem, e.g. there are articles which detail the efficacy of mindful meditation in dealing with anxiety (Semple, Reid \& Miller, 2005). Education pertaining to spiritual interventions must emphasise the ethical constraints in terms of their use in practice. Conditions for the use of interventions - e.g. that the client has expressed an interest in same and that a spiritually sensitive relationship has been developed (Canda \& Furman, 1999) - are important when using spiritual interventions and should be included in education. Empirical work indicating that students in the United States and Britain are utilising certain interventions - e.g. praying with a client, touching clients for healing purposes (Gilligan \& Furness, 2006; Sheridan \& Amato-von Hemert, 1999) - reflect the need for education to distinguish between those with therapeutic benefits and those inappropriate in a social work context. Spiritually-based interventions are best discussed in conjunction with practice and ethical issues.

\section{COLLABORATION AND NETWORKING WITH RELIGIOUS AND SPIRITUAL ORGANISATIONS}

(Work effectively with social workers and members of inter-sectoral and multi- and/or interdisciplinary teams in social service delivery.)

Over $70 \%$ of the sample supported the need for education to focus on collaboration with religious and spiritual organisations. This type of networking is relevant to macro- and micropractice issues. Cnaan, Boddie and Danzig (2005a) contended that clergy and congregational members are familiar with community needs and often plan activities to serve those in need. Many people facing illness, job loss, traumas and financial hardships find solace in spiritual organisations and their personal spiritual beliefs. Cnaan et al. (2005a) argued for the training of students to work in and with faith-based organisations so as to be competent in addressing client's spiritual needs and working with faith-based providers to develop social services. They suggested that students receive lectures that cover faith-based social service delivery and the place of organised religion in the complex network of social service delivery.

\section{FUNCTIONAL/DYSFUNCTIONAL RELIGIOUS/SPIRITUAL BELIEFS AND BEHAVIOUR PATTERNS}

(Assess client systems' social functioning.)

Almost $70 \%$ of the sample saw the importance of including the functional and dysfunctional aspects of spirituality. Spirituality is often ignored during assessment, resulting in spiritual resources and strengths being ignored during intervention. Similarly the dark side of religion, e.g. fundamentalism, religious ideation and involvement with negative cults, is an important consideration in client wellbeing (Bhagwan, 2002).

At a macro-level fundamentalism has been associated with community and international violence war and terror (Cnaan et al., 2005a; Derezotes, 2009). According to Orsi, social workers should be "ecologically based relationship builders" and should "strive to help foster the religious (and spiritual) development of each person so that he or she can become more respectful of religious diversity" in the world (in Derezotes, 2009:72-73). Practitioners therefore need to assume roles that foster non-violence, understanding and cooperation (Derezotes, 2009), roles for which education needs to prepare students. 


\section{RELIGIOUS PERSPECTIVES ON POLICY ISSUES}

(Identify, select and implement various techniques, methods and means of raising awareness, developing critical consciousness about the structural forces of oppression, exclusion and disempowerment, and use such awareness to engage people as change; demonstrate understanding of how social welfare policy and legislation are developed and influenced.)

Sixty-seven percent of the sample supported the inclusion of religion and policy in spirituality curricula. Curricula material should seek to connect spirituality and religion with social welfare, politics and social policy development (Bhagwan, 2002). Seyfried (2007) lamented that although social work values social justice, little is done around practising social justice. She argued that spirituality classes creates the opportunity to link formal and informal policies, organisational culture and politics to advocacy efforts by creating awareness that we are interconnected and interdependent, and should extend our meaning and purpose beyond selfinterest.

Curricula can focus on current policy debates amongst varied religious groups, current debates between secular and religious perspectives; historical religious influences on social policy and programmes in different countries such as Islamic traditions in the Middle East, Buddhism in Asian countries and spiritual traditions among First Nations peoples in North America concerning democracy; alternative perspectives on spirituality and the ways in which social support systems are influenced by religious traditions (Furman et al., 2004).

\section{THE HISTORICAL RELIGIOUS OR SPIRITUAL ROOTS OF THE PROFESSION}

(Demonstrate social work values while interacting with human diversity.)

Sixty-five percent of the current sample supported the need for content on the historical religious or spiritual roots of the social work profession. The historical background need not be comprehensive, but should be linked to the development and current status of religion and spirituality in social work. The time-related phases connecting religion and spirituality to the development of, for example, American social work can be highlighted (Canda \& Furman, 1999). Material which traces the development of the field in South Africa would also add value to the course and help students connect more meaningfully with religion and spirituality in social work in South Africa. Noyoo (2000), for example, pointed out the role of religious organisations such as the Dutch Reformed Church in taking the lead in ameliorating the poor white problem.

\section{DEVELOPMENTAL THEORIES OF SPIRITUAL AND RELIGIOUS GROWTH}

(Access and utilise resources appropriate to client systems' needs and strengths.)

Sixty-five percent of the sample supported the inclusion of developmental theories in spirituality curricula. Erikson's stage theory of human development, Fowler's cognitivestructural faith development theory (Canda \& Furman, 1999) and Ken Wilber's transpersonal spectrum model of development (Bhagwan, 2007a) are most relevant to understanding religious and spiritual growth and can be drawn upon in classroom discussions. Northcut cautioned, however, on the need to move beyond linear approaches to understanding spirituality, but rather to move towards multiple ways of understanding spirituality. She recommended the work of Weingarten, who wrote about the opportunities for spiritual practice, and Cornett's The soul of psychotherapy (2005:49). 


\section{TRANSPERSONAL SOCIAL WORK}

\section{(Access and utilise resources appropriate to client systems' needs and strengths.)}

Information pertaining to transpersonal social work received the lowest level of support for inclusion in the proposed course. Students are unaware of this field and may therefore have underscored its importance to practice and education (Bhagwan, 2007a). Students indicated that transpersonal theory (52\%), transpersonal healers $(51 \%)$ and transpersonal experiences $(50 \%)$ specifically should be included. Transpersonal theory is important, because it would allow social workers to address the trans-egoic levels of development of the client (Bhagwan, 2007a). Clients use transpersonal healers extensively. African clients are known to consult with transpersonal healers, traditionally known as sangomas and inyangas, whilst Hindu clients seek the assistance of "spiritual masters or temple priests". An understanding of transpersonal healing (Cooperstein, 1992) and the role of such healers are salient areas for transpersonal social work education or spiritual diversity.

The separation of genuine transpersonal experiences from psychopathology is critical to the process of differential clinical assessment and should be incorporated into education (Bhagwan, 2007a). Almost $60 \%$ of the sample supported the need for the proposed course to include diagnostic skills to distinguish between genuine religious and/or spiritual transpersonal experiences and psychopathology. This is most relevant to the aforementioned guidelines on religious/spiritual issues in practice and diversity. Schizophrenia, bipolar disorder and severe depression are often characterised by delusions, hallucinations and preoccupations with religious themes or images akin to transpersonal experiences. Hence, when clients in crisis begin to describe spiritual experiences, social workers may question the nature of reality and visions experienced (Canda \& Furman, 1999). The nature and types of transpersonal experiences and the skills to distinguish between the two have been elucidated by Bhagwan (2007a) and this work can be utilised to facilitate education in this area.

\section{CONCLUSION}

Findings from this study are important as they reflect one of the only empirical enquiries in this field nationally. The guidelines presented can be seen to create a pathway for incorporating spirituality into education in South Africa. The data reflect greater support for spiritual diversity and micro-practice issues as opposed to macro-practice issues. Both domains in tandem with research, however, need to be considered in a holistic approach to spirituality. The content areas supported by the sample create a valuable skeletal framework around which curricula on spirituality and social work can be built. In addition, the growing literature can serve to guide South African educators. Papers e.g. "Spirituality: What we can teach and how we can teach it" (Rothman, 2009) and "Ethical issues in the use of spiritually based interventions in social work practice: what are we doing and why?" (Sheridan, 2008) are useful resources. A recently published book titled: Spiritually oriented social work practice (Derezotes, 2006) also provides in-depth information on spirituality in social work and can be used in education. Locally a comprehensive set of guidelines to facilitate curricula development has been developed by Bhagwan (2002).

In the United States spirituality has been offered as an elective. Whilst it is not suggested that this be implemented, it is important that issues of spirituality do not continue to remain separated from education. Without the appropriate knowledge and skills practitioners will remain unprepared to deal with the spiritual dimension in practice. Research undertaken in South Africa, Britain and the United States confirms that students are receptive to spirituality in education (Bhagwan, 2002; Gilligan \& Furness, 2006; Sheridan \& Amato-von Hemert, 1999). 
While aspects such as diversity may be a part of current curricula, this study has unearthed other important areas that need integration.

Content on religion and spirituality can be effectively integrated horizontally and vertically into all educational levels. Horizontal integration is the process of interrelating religious and spiritual content with content taught in all other concurrent classes (Derezotes \& Evans, 1995). This has been illuminated in the current paper in terms of the exit-level outcomes. Vertical integration is the process of gradually expanding the educational component as the student moves through the educational levels. For example, definitions of religion and spirituality, spiritual diversity and principles of spiritually-sensitive work can be taught at first-year level, micro-practice issues in the second year, and religion and policy at third-year level (Derezotes \& Evans, 1995).

This paper serves as an important starting point for a more rigorous consideration of spirituality in research and education. Greater empirical work on how spirituality manifests and shapes clients' experiences, the views of practitioners with regard to practice challenges and those of educators with regard to the challenges to bring it into the educational domain will widen the lens offered by this paper in terms of what to teach and how to teach it in South Africa.

\section{RFEFERENCES}

AMERICAN PSYCHIATRIC ASSOCIATION. 1994. Diagnostic and statistical manual of mental disorders $\left(4^{\text {th }} \mathrm{ed}\right)$. Washington DC: American Psychiatric Association.

BETHEL, J.C. 2004. Impact of spirituality courses on student attitudes, values, and spiritual wellness. Journal of Religion and Spirituality in Social Work, 23(4):27-45.

BHAGWAN, R. 2002. The role of religion and spirituality in social work practice: guidelines for curricula development at South African Schools of Social Work. Durban: University of Natal. (PhD Dissertation)

BHAGWAN, R. 2007a. Awakening to the Transpersonal Paradigm: Discerning transcendent experiences from pathology. Social Work/Maatskaplike Werk, 43(4):366-376.

BHAGWAN, R. 2007b. Tools and techniques to facilitate spiritually sensitive clinical assessment and intervention. The Social Work Practitioner-Researcher, 19(3):25-40.

BHAGWAN, R. 2009. Creating sacred experiences for children as pathways to healing, growth and transformation. International Journal of Children's Spirituality, 14(3):225-234. (in press).

BIANCHI, E. 2005. Living with elder wisdom. Journal of Gerontological Social Work, 45:319-329.

CANDA, E.R. 1989. Religious content in social work education: a comparative approach. Journal of Social Work Education, 1:36-45.

CANDA, E.R. \& FURMAN, L.D. 1999 Spiritual diversity in social work practice: The heart of helping. New York: The Free Press.

CANDA, E.R., NAKASHIMA, M. \& FURMAN, L.D. 2004. Ethical Considerations about spirituality in social work: insights from a national qualitative survey. Families in Society, 85(1):27-35. 
CARROLL, M.M. 2001. Conceptual models of spirituality. In: CANDA, E.R. \& SMITH, E.D. (eds) Transpersonal perspectives on spirituality in social work. New York: The Haworth Press Inc.

CNAAN, R.A., BODDIE, S.C. \& DANZIG, R.A. 2005a. Teaching about organized religion in social work: lessons and challenges. Journal of Religion and Spirituality in Social Work, 24(1/2):93-110.

CNAAN, R.A., BODDIE, S.C. \& KANG, J.J. 2005b. Religious congregations as social service providers for older adults. Journal of Gerontological Social Work, 45(1/2):105-130.

COOPERSTEIN, M.A. 1992. The myths of healing: A summary of research into transpersonal healing experiences. The Journal of the American Society for Psychical Research, 86:99133.

DEREZOTES, D.S. 2006. Spiritually oriented social work practice. USA: Pearson Education Inc.

DEREZOTES, D. 2009. Religious resurgence, human survival, and global religious social work. Journal of Religion and Spirituality in Social Work, 28:63-81.

DEREZOTES, D.S. \& EVANS, K.E. 1995. Spirituality and religiosity in practice: in-depth interviews of social work practitioners. Social Thought, 18(1):39-56.

DUDLEY, J. \& HELFGOTT, C. 1990. Exploring a place for spirituality in the social work curriculum. Journal of Social Work Education, 26:287-294.

EWING, W.A. 2005. Land of forgetfulness: Dementia care as spiritual formation. Journal of Gerontological Social Work, 45:301-311.

FURMAN, L.D., BENSON, P.W., GRIMWOOD, C. \& CANDA, E.R. 2004. Religion and spirituality in social work education and direct practice at the millennium: a survey of UK social workers. British Journal of Social Work, 34:767-792.

FURMAN, L.D., BENSON, P.W., CANDA, E.R. \& GRIMWOOD, C. 2005. A comparative international analysis of religion and spirituality in social work: a survey of UK and US social workers. Social Work Education, 24(8):813-839.

GILLIGAN, P. \& FURNESS, S. 2006. The role of religion and spirituality in social work practice: views and experiences of social workers and students. British Journal of Social Work, 36:617-637.

GRAFF, D.L. 2007. A study of Baccalaureate social work students' beliefs about the inclusion of religious and spiritual content in social work. Journal of Social Work Education, 43(2):243-256.

HODGE, D.R. 2005. Spirituality in social work education: a development and discussion of goals that flow from the profession's ethical mandates. Social Work Education, 24(1):37-55.

HODGE, D.R. 2006. Spiritually modified cognitive therapy: a review of the literature. Social Work, 51(2):157-166.

JACOBS, C. 1997. On spirituality and social work practice. Smith College Studies in Social Work, 67(2):171-175. 
KVARFORDT, C.L. \& SHERIDAN, M.J. 2007. The role of religion and spirituality in working with children and adolescents: results of a national survey. Journal of Religion and Spirituality in Social Work, 26(3):1-23.

LAYTON, E. \& COLLINS, K. 2004. Advancing through retreating: self care among practitioners. Social Work/Maatskaplike Werk, 40(4):430-445.

LOMBARD, A. GROBBELAAR, M. \& PRUIS, S. 2003. Standards for social work qualifications in South Africa. Social Work/Maatskaplike Werk, 39(1):1-17.

MOXLEY, D. P. \& WASHINGTON, O.G.M. 2001. Strengths-based recovery practice in chemical dependency: a transpersonal perspective. Families in Society, 82(3):251-263.

NORTHCUT, T.B. 2004. Pedagogy in diversity: teaching religion and spirituality in the clinical social work classroom. Smith College Studies in Social Work, 74(2):349-358.

NORTHCUT, T.B. 2005. The role of religion and spirituality in clinical social work: creating a space for integration in MSW/MDIV Joint Programs. Journal of Religion and Spirituality in Social Work, 24(1/2):45-54.

NOYOO, N. 2000. Preparing South African social workers for social development praxis. Social Development Issues, 22(1):35-41.

REDMAN, D. 2008. Stressful life experiences and the roles of spirituality among people with a history of substance abuse and incarceration. Journal of Religion and Spirituality in Social Work, 27:47-67.

ROTHMAN, J. 2009. Spirituality: what we can teach and how we can teach it. Journal of Religion and Spirituality in Social Work, 28:161-184.

SEMPLE, R.J., REID, E.F.G. \& MILLER, L. 2005. Treating anxiety with mindfulness: an open trial of mindfulness training for anxious children. Journal of Cognitive Psychotherapy: An International Quarterly, 19:4:379-392.

SEWPAUL, V. \& JONES, D. 2005. Global standards for the education and training of the social work profession. International Journal of Social Welfare, 14:218-230.

SEYFRIED, S.F. 2007. Creating a diverse spiritual community: reflections from a spirituality and social work practice class. Journal of Ethnic and Cultural Diversity in Social Work, 16(3/4):159-167.

SHERIDAN, M.J. 2008. Ethical issues in the use of spiritually based interventions in social work practice: what are we doing and why? Journal of Religion and Spirituality in Social Work, 28:99-126.

SHERIDAN, M.J. \& AMATO-VON HEMERT, K. 1999. The role of religion and spirituality in social work education and practice: a survey of student views and experiences. Journal of Social Work Education, 35(1):125-141.

Dr Raisuyah Bhagwan, Department of Community Health Studies, Faculty of Health Sciences, Durban University of Technology, Durban, South Africa. 